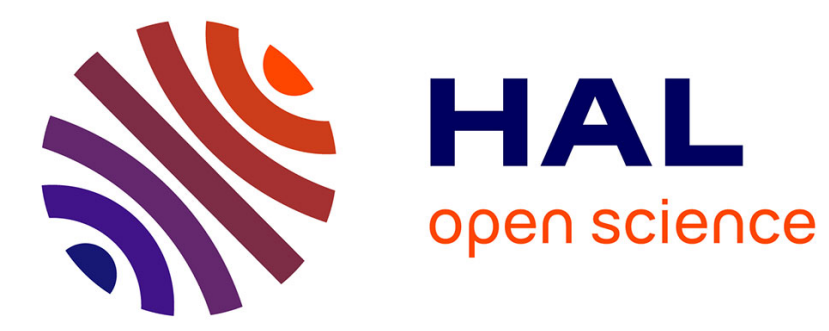

\title{
IoT Acoustic Antenna Development for Fish Biomass Long-Term Monitoring
}

Gabriel Vasile, Teodor Petrut, Guy d'Urso, Eric de Oliveira

\section{To cite this version:}

Gabriel Vasile, Teodor Petrut, Guy d'Urso, Eric de Oliveira. IoT Acoustic Antenna Development for Fish Biomass Long-Term Monitoring. OCEANS 2018 - OCEANS '18 MTS/IEEE. Healthy Oceans, Resilient Coasts, Robust Commerce... Strong Nations, Oct 2018, Charleston, United States. hal01935311

\section{HAL Id: hal-01935311 https://hal.science/hal-01935311}

Submitted on 26 Nov 2018

HAL is a multi-disciplinary open access archive for the deposit and dissemination of scientific research documents, whether they are published or not. The documents may come from teaching and research institutions in France or abroad, or from public or private research centers.
L'archive ouverte pluridisciplinaire HAL, est destinée au dépôt et à la diffusion de documents scientifiques de niveau recherche, publiés ou non, émanant des établissements d'enseignement et de recherche français ou étrangers, des laboratoires publics ou privés. 


\section{IoT Acoustic Antenna Development for Fish Biomass Long-Term Monitoring}

\author{
Gabriel Vasile, Teodor Petrut \\ Grenoble-Image-sPeech-Signal-Automatics Lab \\ CNRS / Université Grenoble Alpes \\ 11 rue des Mathématiques \\ Grenoble Cedex, France, F-38402 \\ gabriel.vasile@gipsa-lab.grenoble-inp.fr
}

\author{
Guy d'Urso and Eric De Oliveira \\ Electricité de France \\ EDF R\&D, STEP / LNHE \\ 6 quai Watier \\ Chatou, France, F-78400 \\ guy.durso@edf.fr, eric.de-oliveira@edf.fr
}

\begin{abstract}
This paper proposes a novel Internet of Things (IoT) hardware framework for detecting and counting operations for fish biomass estimation. Based on a multi-static configuration, the core part of the system is using a single board computer with high capabilities in ADC and DAC and an analog multiplexer with a competitive switching rate.
\end{abstract}

\section{INTRODUCTION}

Hydropower plants have important effects on migrating fish species as they can perturb and even block the migration and thus contribute to the decline and even the extinction of species. Allowing hydropower plants and river system biodiversity coexisting is a challenge, which requires sustainable solutions touching economic, social and environmental aspects. The European Commission published proposals for regulation by which passage channels are used to by-pass the fish migration paths and to permit the upstream migration of salmon and trout species [1]. Among the environmental risk mitigation measures, fish passes and downstream bypass are of increasing importance for the restoration of free passage for fish and other aquatic species in rivers.

Bypass channels provide a way to completely circumvent the undesired barrier to fish migration. It is designed to match any side channel of the main river system both in form and function. Bypass channels mainly used to small scale barriers such as low head weirs $(<2 \mathrm{~m})$, where the height difference between up and downstream does not lead to an overly long bypass section. More technical details can be found in [2].

Fish passes represent a range of in-channel structures designed to facilitate the upstream and downstream movement of fish and other aquatic fauna. Fish passes are applied to watercourses where natural (or human) obstructions such as dams, weirs, or culverts prevent or interfere with fish migration. Such fish passage problems can occur at almost any site where the water level difference between upstream and downstream of the structure is higher than about $0.5 \mathrm{~m}$ [3]. An extensive presentation of French fish passes types can be found in [4].

The monitoring of fish passages in a channel could be done using different technologies, like camera filming, infrared systems, passive sonars, active acoustic tagging or RFID tagging [5]. In this work, we propose a $500 \mathrm{kHz}$-acoustic system for counting fishes in passage channels, which operates on the principle of multi-static acoustic antenna [6], [7]. The current system was developed in collaboration between the GIPSA-lab and the EDF R\&D. It is composed of several acoustic barriers: each fish passage will obstruct the acoustic propagation channel between the emitter and the receiver, which makes possible fish monitoring. Each acoustic barrier can act as an independent conventional immersed wideband ultrasound system in bistatic configuration, also.

In the same time, emerging Internet of Things (IoT) solutions provide nowadays a new perspective both in terms of cost reduction and remote operation capabilities. Because the passage channel is a highly noisy and relatively fast changing environment, our motivation for designing the proposed IoT system is to increase the quality of signals and to simplify the computational load of the processing algorithms for the detection of events.

The paper is structured as follows. Section II illustrates in several points the general hardware architecture proposed for the fish monitoring system, while Section III presents some qualitative and quantitative performance assessment. Section IV concludes the paper.

\section{IOT HARDWARE ARCHITECTURE}

The main advantages of the proposed acoustic system, as compared to commercial active acoustic systems are: cost effectiveness and minimal preparations for on site installation. The designed configuration schematic is shown in Fig. 1(a),(b).

As it can be observed, three modules are composing the IoT fish monitoring system:

- the IoT client - an embedded system capable of managing signal acquisition, real time processing (intelligent triggering option) and sending the recorded data to the server ;

- the IoT hub - a processing unit for data management, storage and final signal processing ;

- Ultrasound transducers and electronic conditioning.

In the remaining part of this section, we provide more in depth details on these modules. 




Fig. 1. Setup configuration developed for the fish counting application: (a) global set-up and (b) data processing modules.

\section{A. IoT client embedded system}

The proposed system uses one of the most advanced single board computer on the market, Red Pitaya STEMLab 125-14 (RP), which contains a system-on chip (SoC) composed of the Xilinx FPGA, with an ARM Cortex A9 processor, 256 MB RAM and ports for $1 \mathrm{~Gb} / \mathrm{s}$ Ethernet communication. The board has 2 fast analog inputs and 2 fast analog outputs, which allows analog-to-digital conversion up to 14 bits and 125 $\mathrm{MHz}$ sampling frequency. This is more than suitable for using ultrasound frequencies around $500 \mathrm{kHz}$ (or lower). Giving the fact that the board has only 2 analog inputs, we propose to use an analog multiplexer: a Texas Instruments MUX36D04 containing 2:8 (2 input channels to 8 output channels) or 1:4 multiplexing capability (Round Robin or sequential sampling). At its full potential, the multiplexer can switch channels at about 100 ns. In this very first version of the system we use the Red Pitaya's outputs digital pins to command the TI multiplexer. Therefore, by means of analog multiplexing, we are able to set up to 8 physical ultrasound paths, or acoustic barriers across the passage channel. In the next version, both the analog multiplexing and the acquisition are to be driven by an external digital pattern generator (Arduino Due).

\section{B. IoT hub and server processing unit}

We have used as IoT data collection hub and real-time signal processing an Intel Next Unit of Computing equipped with i5 $7260 \mathrm{U}$ processor, $8 \mathrm{~GB}$ of RAM and $256 \mathrm{~GB}$ of SSD storage. The server is connected to the IoT client via Gigabit Ethernet (by a direct cable or by a wireless USB 2.0 dongle). The communication is established either by direct TCP / IP with fixed IP addresses or via a LAN router.

In a separate paper, we discuss the software architecture and the signal processing algorithms for the fish monitoring in the respective passage channel.

\section{Ultrasound transducers and electronic conditioning}

Like any other acoustic acquisition and processing system, it comprises the standard stages of a conventional active emission-reception configuration. The system is bi-static, which means we use two emitters (Ultran Group WS-1001) and 2 receivers (Ultran Group KS-100-1) face-to-face to establish two acoustic barriers across the passage channel. The emitted signal has been amplified by a power amplifier APEX Microtechnology PA107 (gain at $20 \mathrm{~dB}$ ), whereas the received signal has been conditioned by a low noise amplifier (Texas Instruments VCA 5807).

\section{RESUlTS AND Discussion}

Pilot tests have been already applied on the system in a controlled passage channel with fishes inside. The test and measurement campaign has been realised within the EDF R\&D facilities, Chatou, France, in 2018. The setup of the ultrasound transducers is shown in Fig. 2. In order to validate the obtained fish detection results, an underwater camera has been installed, also.

In our 3-day experiment, the IoT client has been programmed to continuously transmit two types of arbitrary waveforms in burst mode: sine-wave with a squared weighting window and linear chirp with Hamming weighting window 


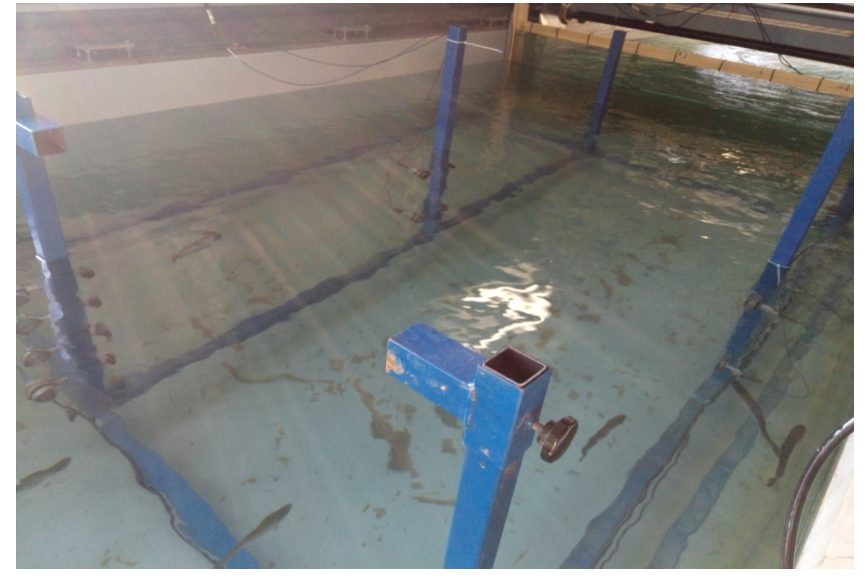

(a)

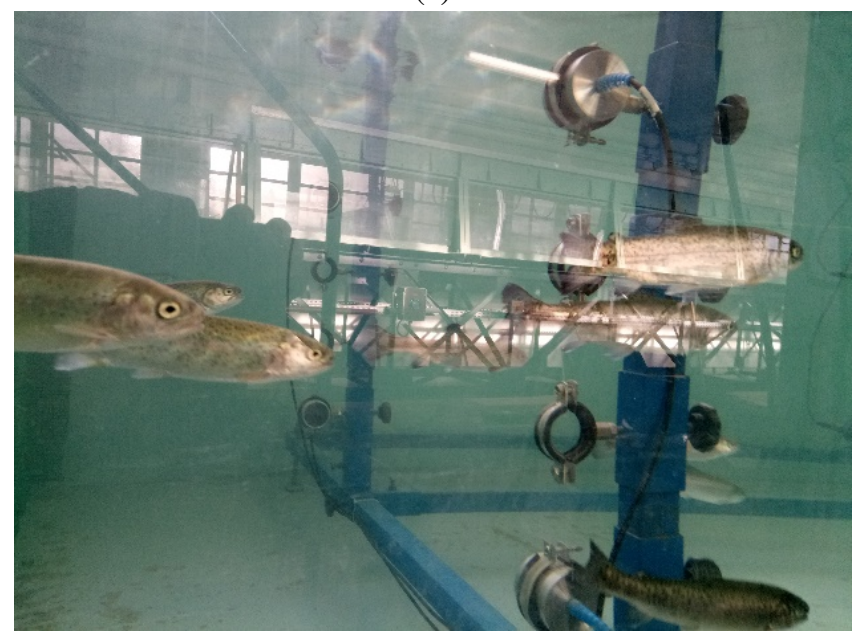

(b)

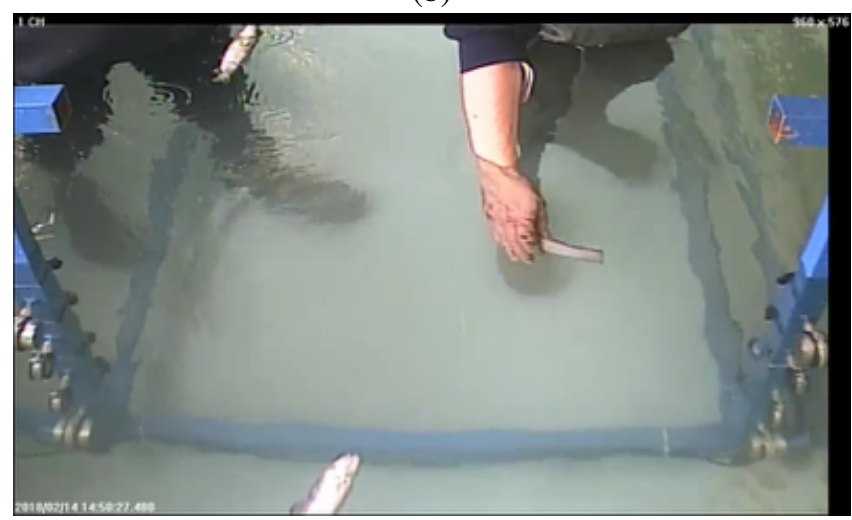

(c)

Fig. 2. Ultrasound transducers installed on Channel 12 at the EDF R\&D: (a) global view, (b) trout passage and (c) underwater camera photo.
[9]. Two samples of the received signals are illustrated in Fig. 3 and Fig. 4. One can notice the signal level on the second acoustic barrier (lower depth) is approximately half on the first one (upper depth). This has been used in order to evaluate the impact of the signal level variations on the fish monitoring result.

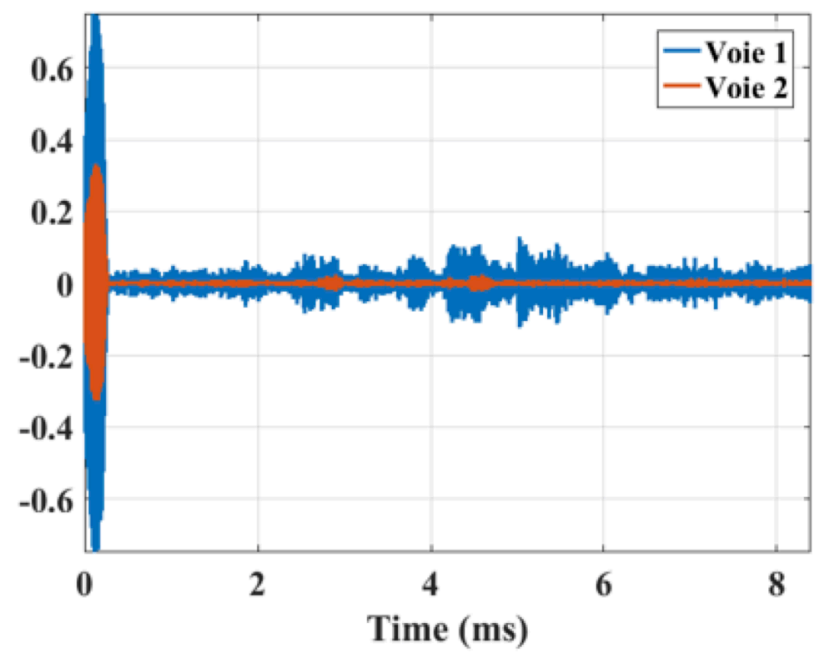

(a)

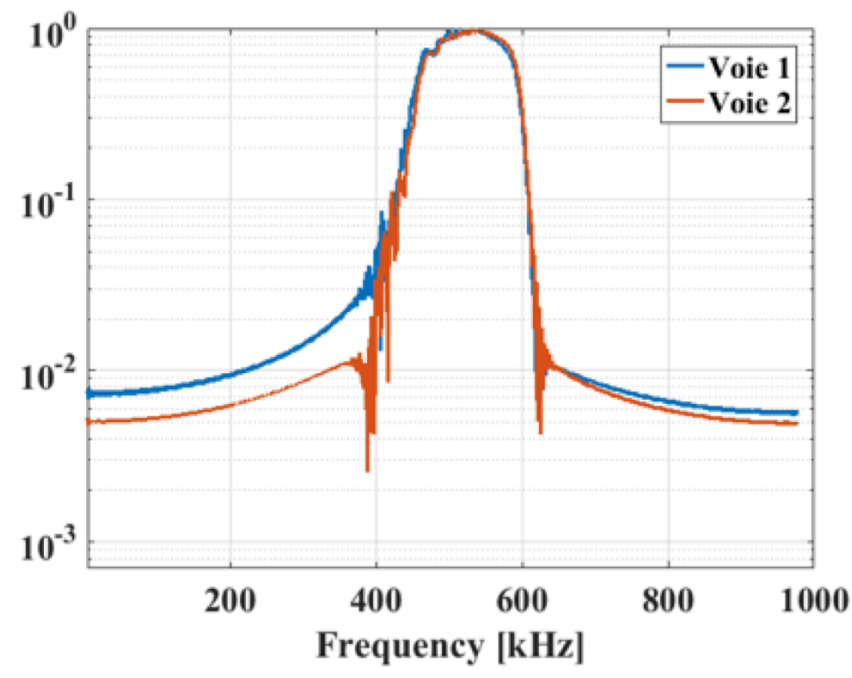

(b)

Fig. 3. Ultrasound chirp signals received by the IoT client and retrieved via the IoT hub : (a) time domain and (b) frequency domain - normalized amplitude.

At the IoT hub level, the demodulation by normalized crosscorrelation (match filtering with the non-linearity corrected reference from [10]) is performed, also: the peak value for each burst is recorded in order to construct the associated time series for fish monitoring. The obtained detection results, which have been validated using the installed underwater camera are illustrated on Fig. 5 for one night of continuous monitoring.

One can observe the monitored fish activity is decreasing dramatically during nighttime. More acoustic detections have been obtained by the lower depth barrier indicating that the 


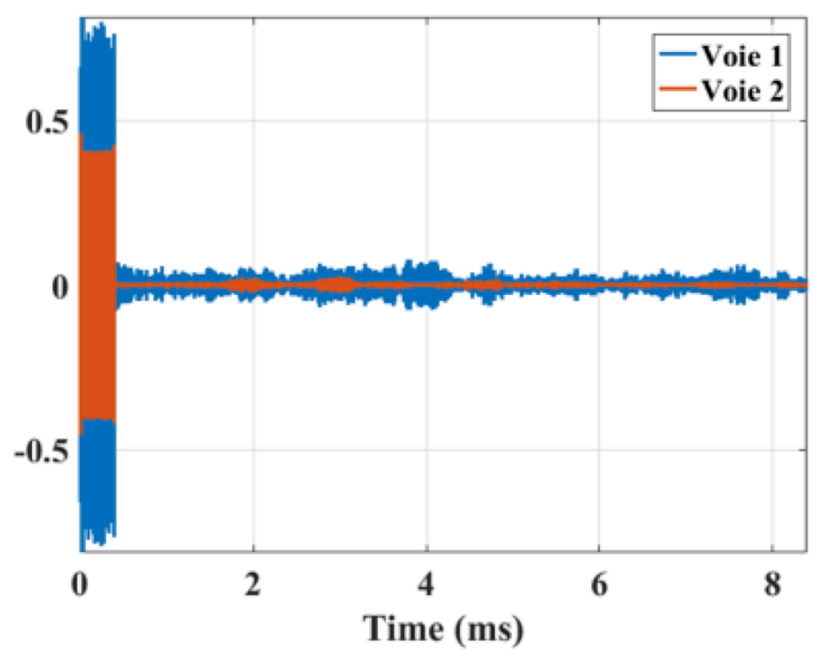

(a)

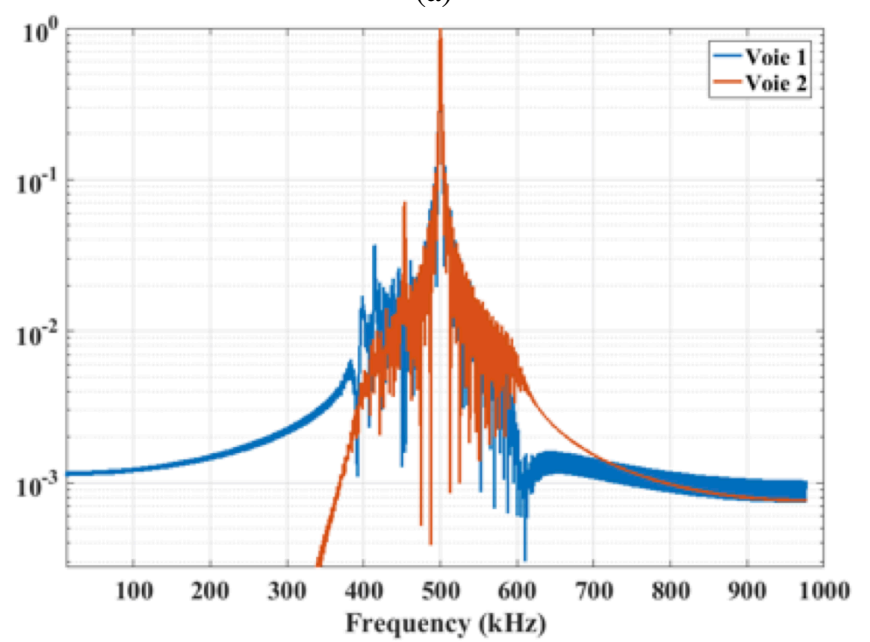

(b)

Fig. 4. Ultrasound sine-wave signals received by the IoT client and retrieved via the IoT hub : (a) time domain and (b) frequency domain- normalized amplitude.

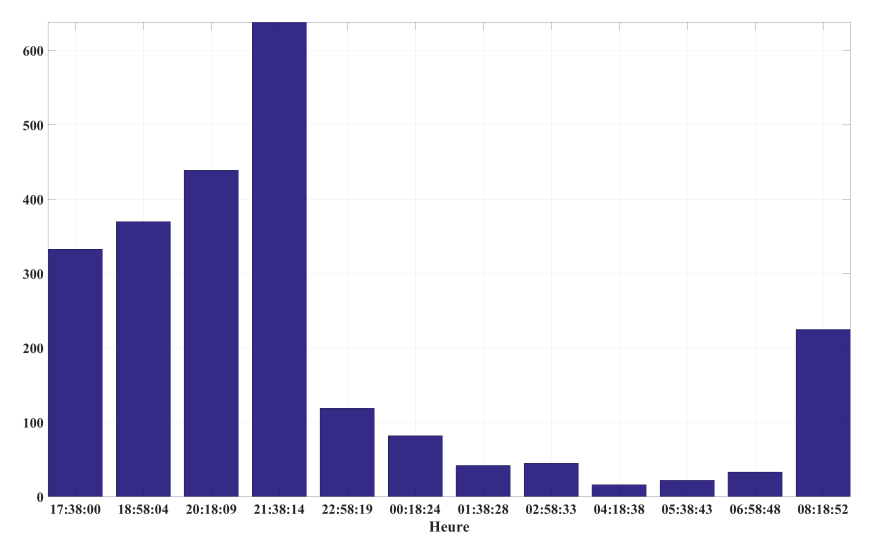

Fig. 5. Ultrasound sine-wave signals received by the IoT client and retrieved via the IoT hub : (a) time domain and (b) frequency domain- normalized amplitude. weaker signal level has no significant impact on the proposed algorithm.

\section{CONCLUSION}

In conclusion, a low power consumption and cost effective IoT acoustic system was designed to achieve monitoring of fish passages in channels near hydropower plants or dams. The system is based on a multi-static configuration of 1 emitter to 4 receivers or 2 emitters to 8 receivers. The core part of the system is using a single board computer with high capabilities in ADC and DAC operations and an analog multiplexer with a competitive switching rate. The IoT system was tested for real-time operations and proved to be very robust with respect to signal acquisition, data transmission to the server and real-time signal processing. The main scope is fish detection and counting, but further applications like classification or localisation could be added. The future tests will also include the multiplexing stage in order to increase the number of acoustic barriers across the passage channels.

\section{ACKNOWLEDGMENT}

This work has been developed in the framework of the ACOUEAU project, supported by the European Union Regional Development Fund, the SCANUS project, supported by the SATT LINKSIUM Grenoble Alpes, and the Scientific Equipment 2017 AO project, supported by the LabEx OSUG@2020. The authors would like to thank to Gelu Ionescu, Steeve Zozor, Amaury Nègre and Pascal Bellemain, form the GIPSA-lab, and to Géry Hachet and Alexandre Girard, from the EDF R\&D, for their precious support in hardware and software development.

\section{REFERENCES}

[1] ESHA European Small Hydropower Association, "Strategic study for development of small hydropower in the European Union," Tech. Rep. Renewable Energy House, 2008.

[2] M. Larnier, "Pool fishways, pre-barrages and natural bypass channels," Bulletin Français de la Pêche et de la Pisciculture, vol. 364, pp. 54-82, 2002.

[3] Environment Agency, "Environment Agency annual report and accounts 2009 to 2010," Tech. Rep., 2010.

[4] F. Aigoui and M. Dufour, "Guide Passes poissons - Voies navigables de France," Tech. Rep., Voies navigables de France, division Restauration et Développement du Réseau (in French), 2008.

[5] M. Cuchet, M. Muhlbauer, C. Ratschan, A. Hartlieb, and B. Brinkmeier, "Behavioural experiments on the design of downstream fish passage facilities for potamodromous species," in Proceedings of the IAHR World Congress - Balance and Uncertainty, Brisbane, Australia, 2011, pp. 2792 2798.

[6] G. Vasile, G. d'Urso, E. de Oliveira, J. Guillet, and E. Lungu, "Reference selection for an active ultrasound wild salmon monitoring system," in Proceedings of the MTS/IEEE North American OCEANS conference, Washington, DC, USA, 2015, pp. 1-4.

[7] G. Vasile, E. Trouvè, M. Ciuc, P. Bolon, and V. Buzuloiu, "Intensitydriven-adaptive-neighborhood technique for POLSAR parameters estimation," in Proceedings of the IEEE Geoscience And Remote Sensing Symposium, Seoul, Korea, 2005, vol. 8, pp. 5509-5512.

[8] G. Vasile, G. d'Urso, E. de Oliveira, and E. Lungu, "Transmission waveform analysis for active ultrasound fish monitoring systems," in Proceedings of the MTS/IEEE North American OCEANS conference, Anchorage, Alaska, USA, 2017, pp. 1-4.

[9] G. Vasile, G. d'Urso, E. de Oliveira, and E. Lungu, "Online software nonlinearity correction for wideband active ultrasound monitoring systems," in Proceedings of the MTS/IEEE North American OCEANS conference, Anchorage, Alaska, USA, 2017, pp. 1-4. 